\title{
Determination of Thyroid Disorders in the Human Body using TSH, T3 and T4 Levels
}

\author{
Yash Pal \\ Dept. of CSE \\ RIET \\ Phagwara, Punjab
}

\author{
Vikas Verma \\ Dept. of CSE \\ Lovely Professional University \\ Phagwara, Punjab
}

\author{
Rishma Chawla \\ Dept. of CSE \\ RIET \\ Phagwara, India
}

\begin{abstract}
This is an endeavour to simulate the concept of determining type of Thyroidism after stipulating the TSH, T3 and T4 levels in the human body by using proposed analog circuit. The Analog devices like operational amplifiers have behaviour similar to the mathematical operations. Till date there are so many software - based techniques used for determination of effective dose to be provided to the patient so that normal level of Thyroxine can be maintained in the human body [1]. There is a need for hardware-oriented analog device to provide an accurate and efficient mean for calculation of effective dose amount and TSH, T3 and T4 values can be used. Basically, the voltages in the high-gain dc amplifiers are equated to these three variables and the operational amplifiers can do the mathematical operations on the voltages, although the accuracy of measuring voltage is limited to certain point. The simulation has been done using CircuitMaker.
\end{abstract}

\section{Keywords}

TSH (Thyroid Stimulating Hormones), T4( Thyroxine), T4( Tri-iodothyronine) and OPAMPs

\section{INTRODUCTION}

The thyroid is a gland in the Human neck which generates two thyroid hormones, thyroxine (T4) and Tri-iodothyronine (T3). Thyroxine (T4) is passive and is converted by the tissues and organs that need it into tri-iodothyronine (T3) [2]. The role of thyroid hormones are required to regulate the metabolism of indirectly all the cells in the body. When there is not sufficient thyroid hormone (hypothyroidism) the body's metabolism reduces and this is reflected by changes in various tissues that are listed here [3]. About $80 \%$ of tri-iodothyronine in the body is derived from conversion of thyroxine in the tissues (a process mediated by deiodinase enzymes), the remainder coming directly from the thyroid gland. The free fraction of T4 and T3 in the blood is therefore a more useful measure of thyroid hormone levels than the total amount of these hormones. This is what is meant by free T4 (FT4) and free tri-iodothyronine (FT3).Thus Thyroxine level determines whether a Human Body is suffering Thyroid disorder or not. The normal ranges for these variables can be given as in Table I.

Different values of these variables make different types of thyroid disorders as given in Table II.
TABLE I

NORMAL RANGES

\begin{tabular}{|c|c|}
\hline VARIABLES & NORMAL RANGES \\
\hline TSH & $0.3-3.0(\mathrm{MIU} / \mathrm{L})$ \\
\hline TOTAL T4 & $4.5-12.5(\mathrm{NG} / \mathrm{DL})$ \\
\hline FREE T4 & $0.7-2.0$ \\
\hline TOTAL T3 & $0.60-1.81(\mathrm{NG} / \mathrm{ML})$ \\
\hline FREE T3 & $2.3-4.2$ \\
\hline
\end{tabular}

TABLE II

TYPES OF THYROID DISORDERS

\begin{tabular}{|c|c|c|c|}
\hline $\mathrm{TSH}$ & $\mathrm{T} 3$ & $\mathrm{~T} 4$ & EXPECTED DISORDER \\
\hline $\mathrm{HIGH}$ & $\mathrm{HIGH}$ & $\mathrm{HIGH}$ & $\begin{array}{c}\text { HYPERTHYROIDISM OR MAY BE } \\
\text { PITUITARY TUMOR }\end{array}$ \\
\hline Low & Low & Low & $\begin{array}{c}\text { SECONDARY HYPOTHYROIDISM OR } \\
\text { MAY BE PITUITARY FAILURE }\end{array}$ \\
\hline $\mathrm{HIGH}$ & NORMAL & NORMAL & $\begin{array}{l}\text { MILD SUBCLINICAL } \\
\text { HYPOTHYROIDISM }\end{array}$ \\
\hline $\mathrm{HIGH}$ & Low & Low & $\begin{array}{c}\text { PRIMARY, FULL-BLOWN } \\
\text { HYPOTHYROIDISM }\end{array}$ \\
\hline $\begin{array}{l}\text { VERY } \\
\text { LOW }\end{array}$ & $\mathrm{HIGH}$ & $\mathrm{HIGH}$ & $\begin{array}{c}\text { MAY BE ON REPLACEMENT } \\
\text { THERAPY OR HYPERTHYROIDISM }\end{array}$ \\
\hline Low & NORMAL & NORMAL & MILD HYPERTHYROIDISM \\
\hline $\mathrm{HIGH}$ & NORMAL & Low & $\begin{array}{l}\text { MAY BE SECONDARY } \\
\text { HYPOTHYROIDISM }\end{array}$ \\
\hline
\end{tabular}

Until November 2002, doctors had relied on a normal TSH level ranging from 0.5 to 5.0 to diagnose and treat patients with a thyroid disorder who tested outside the boundaries of that range [4]. Now AACE encourages doctors to consider treatment for patients who test outside the boundaries of a narrower margin based on a target TSH level of 0.3 to 3.0. AACE believes the new range will result in proper diagnosis for millions of Americans who suffer from a mild thyroid disorder, but have gone untreated until now. Thyroid hormones (T4 and T3) are produced by the follicular cells of the thyroidgland and are regulated by TSH made by the thyrotropes of the anterior pituitary gland [5]. The effects of T4 in vivo are mediated via T3 (T4 is converted to T3 in target tissues). $\mathrm{T} 3$ is 3 - to 5- fold more active than $\mathrm{T} 4$. Thyroxine (Tetraiodothyronine) is produced by follicular cells of the thyroid gland. It is produced as the precursor thyroglobulin (which is not TBG), which is cleaved 
by enzymes to produce active T4 [6]. The steps in this process are as follows:

1. The Na+/I- symporter transports two sodium ions across the basement membrane of the follicular cells along with an iodine ion. This is not a primary active transporter that utilizes the concentration gradient of $\mathrm{Na}+$ to move I- against its concentration gradient.

2. I- is moved through the apical membrane into the colloid of the follicle.

3. Thyroperoxidase oxidises two I- to form I2. Iodide is non-reactive, and only the reactive iodine is required for the next step [7].

4. The thyroperoxidase iodinates the tyrosyl residues of the thyroglobulin within the colloid. The thyroglobulin was prepared in the ER of the follicular cell and sspended into the colloid [8].

5. Thyroid-stimulating hormone (TSH) released from the pituitary gland binds the TSH receptor [9] (a Gs protein-coupled receptor) on the basolateral membrane of the cell and stimulates the endocytosis of the colloid.

6. The endocytosed vesicles fuse with the lysosomes of the follicular cell. The lysosomal enzymes cleave the $\mathrm{T} 4$ from the iodinated thyroglobulin.

7. These vesicles are then exocytosed, releasing the thyroid hormones.

Thyroxine is produced by attaching iodine atoms to the ring structures of tyrosine molecules. Thyroxine (T4) contains four iodine atoms. Triiodothyronine (T3) is identical to $\mathrm{T} 4$, but it has one less iodine atom per molecule [10].

If there is a deficiency of dietary iodine, the thyroid will not be able to make thyroid hormone [11]. The lack of thyroid hormone will lead to decreased negative feedback on the pituitary, leading to increased production of thyroidstimulating hormone, which causes the thyroid to increase the size (the resulting medical condition is called endemic colloid goiter; see goiter). This has the effect of increasing the thyroid's ability to trap more iodide, compensating for the iodine deficiency and allowing it to produce adequate amounts of thyroid hormone [12].

TABLE III

PERCENTAGE OF BOUND THYROXINE [13]

\begin{tabular}{|c|c|}
\hline Type & Percentage \\
\hline Bound to thyroxine-binding globulin (TBG) & $70 \%$ \\
\hline $\begin{array}{c}\text { Bound to transthyretin or "thyroxine-binding } \\
\text { prealbumin" (TTR or TBPA) }\end{array}$ & $10-15 \%$ \\
\hline Albumin & $15-20 \%$ \\
\hline Unbound T4 (fT4) & $0.03 \%$ \\
\hline Unbound T3 (fT3) & $0.3 \%$ \\
\hline
\end{tabular}

If Thyroid Antibodies are tested positive, it indicates that the Thyroid is in the process of Autoimmune failure [14]. It is not failed yet and not failed enough to get registered in the standard Thyroid test but it is in the process of failing.

\section{OPERATIONAL AMPLIFIERS}

An Operational amplifier is the basic element of an analog circuit design. It is a high gain amplifier [15] which has so many applications. The amplifiers can be specified in the terms of gain, input impedance, output impedance, bandwidth, and offset characteristics. These are normally used in amplifier and analog signal processing circuits in frequency band $0 \mathrm{KHz}$ to $100 \mathrm{KHz}$ [16].The OPAMPs which were first developed were vacuum tube circuits used in analog computers. Now OPAMPs are fabricated as ICs(Integrated chips) which are completely different from the earliest OPAMPs.

The Ideal OPAMP is a three-terminal circuit element that is modeled as voltage-controlled voltage source [17]. The OPAMP electronic circuit diagram and circuit symbol (or analog diagram) can be given as in Fig. 1 and Fig. 2. Its output voltage is a gain multiplied by its input voltage. The input voltage is the difference voltage between the two input terminals. The output voltage is measured w.r.t. the circuit ground node.

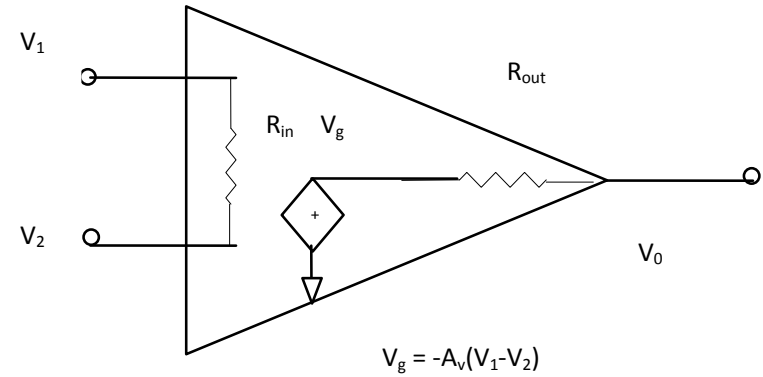

Fig. 1: Ideal Opamp

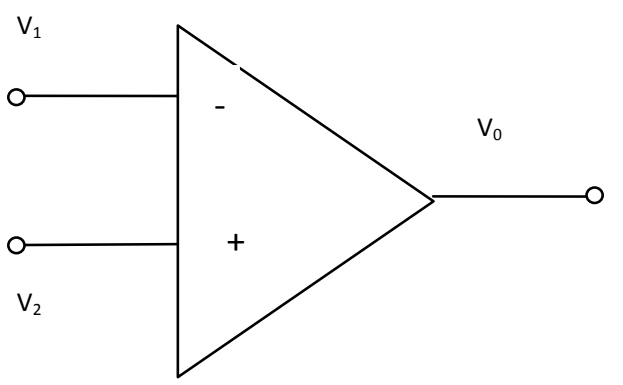

Fig. 2: Ideal Opamp Circuit Symbol

The equation for output voltage can be given as

$\mathrm{V} 0=\mathrm{Av}(\mathrm{V} 2-\mathrm{V} 1)$, where Av is the voltage gain.

$\mathrm{V} 2$ is the voltage at non-inverting input and V1 is the voltage at inverting input. The input terminals have four characteristics, which are

i) There is no current in each input lead.

ii) The output voltage does not depend upon output current.

iii) The voltage gain Av is very large reaching infinity in limit. 


\subsection{Inverting operational amplifier}

The voltage gain is negative, so it is called as an inverting operational amplifier [18]. It implies that if the input voltage is positive, the output voltage will be negative and vice-versa. The input voltage is applied through the resistor R1 to inverting input terminal as shown in Fig. 3. The Resistor Rf is the feedback resistor which connects from the output to the inverting input.

The voltage gain in the inverting OPAMP is given by

$$
\mathrm{V} 0=(-\mathrm{Rf} / \mathrm{R} 1) * \mathrm{~V} 1
$$

\subsection{Summing Operational Amplifier}

The summer circuit actually behaves like the mathematical sum operation [19]. The n-input summer circuit can be shown as Fig. 4. According to the Kirchhoff's law

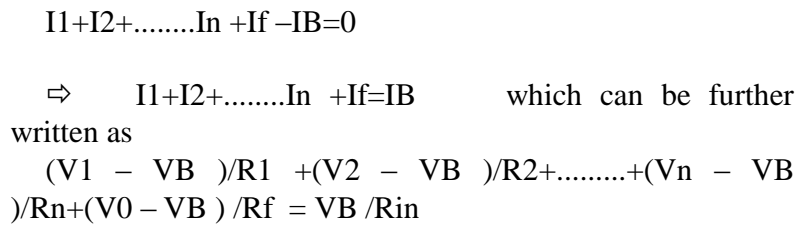

As $\mathrm{Vg}$ can be given as $\mathrm{Vg}=-\mathrm{Av}(\mathrm{V} 1-\mathrm{Vn})$, and also $\mathrm{V} 0=-$ $\mathrm{AvVB}$, so we get

$\mathrm{V} 1 / \mathrm{R} 1+\mathrm{V} 2 / \mathrm{R} 2+$. $. .+\mathrm{Vn} / \mathrm{Rn}+\mathrm{V} 0 / \mathrm{Rf}=-\mathrm{V} 0 / \mathrm{AvRp}$

where $1 / \mathrm{Rp}=1 / \mathrm{R} 1+1 / \mathrm{R} 2+$ $. .1 / \mathrm{Rf}+1 / \mathrm{Rin}$

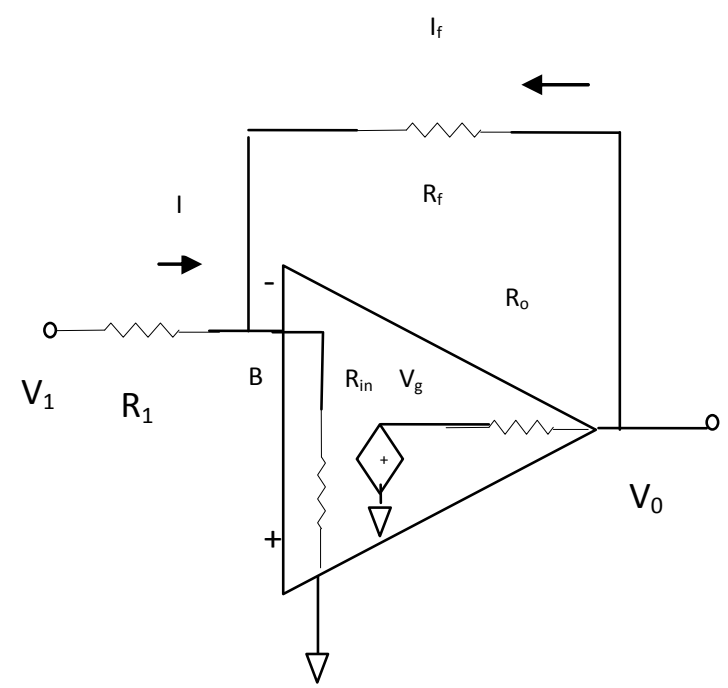

Fig. 3: Inverting Opamp

This operational amplifier has a high voltage gain, so we can consider Av to be infinite. Then the equation (1.2) can be rewritten as

$$
\mathrm{V} 0=-\alpha 1 \mathrm{~V} 1-\alpha 2 \mathrm{~V} 2-\alpha 3 \mathrm{~V} 3
$$
..$\alpha n V n$

where $\alpha i=R f / R i$ and $i=1,2,3, \ldots \ldots \ldots \ldots . . . n$.

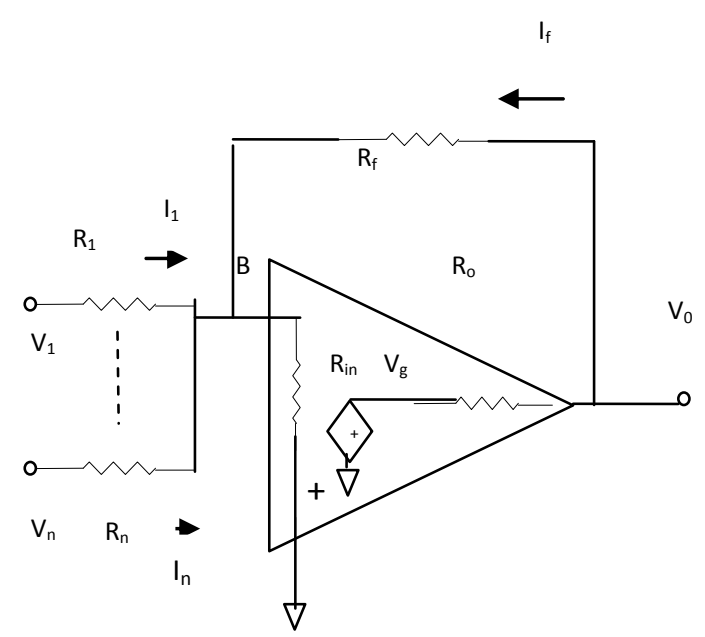

Fig. 4: Summer Circuit

The example of summation of three voltages is shown in Fig. 5 [20]. In this example three resistances (RI, R2, R3) of $20 \mathrm{k} \Omega$ each and $\mathrm{Rf}=200 \mathrm{k} \Omega$ has been used. Thus, $\alpha 1=\alpha 2=\alpha 3=10$. So the summer implements the equation (1.4) as,

$$
\mathrm{V} 0=-10 \mathrm{~V} 1-10 \mathrm{~V} 2-10 \mathrm{~V} 3
$$

\section{THEORETICAL ASPECTS}

To simulate the proposed circuit, we can use an analog method by the use of operational amplifiers. An analog method can be applied to find solutions of a number of differential equations, linear equations etc [16].

The electronic circuit diagram for the proposed device can be given as in Fig. 5 and Fig. 6. There are six Ideal OPAMPs (U1A, U1B, U2, U3, U4, U5) which have been used for implementation of TSH level interpretation. We have implemented four multimeters so that output of each OPAMP can be watched. The Vs1 represents the TSH level of Human Body. If the output of U3 and U4 are both high $(9.984 \mathrm{nV})$ then the TSH level (> $3.0 \mathrm{uIU} / \mathrm{mL})$ is high [21]. If the outputs of both OPAmps are low $(4.898 \mathrm{~V})$ then the TSH level $(<0.3 \mathrm{uIU} / \mathrm{mL})$ is low. If the output of $\mathrm{U} 3$ is high and $\mathrm{U} 4$ is low then the human body is having TSH level in the normal range.

The instance of the circuit shows Vs1 $=0.72 \mathrm{~V}$ that is the TSH level is between normal range. We are representing the single unit of TSH $(1 \mathrm{uIU} / \mathrm{mL})$ by $1 \mathrm{~V}$ of the voltage supplies used in the Fig. 5). In the given circuit, the ideal OPAMP U5 outputs the negative of input Voltage. Thus, the output represents $+\mathrm{TSH}$.

The ideal OPAMP U1A is a comparator. The comparator compares the linear voltage applied on the negative terminal with the voltage applied on the positive voltage. If the voltage on positive terminal is greater than on the negative terminal, the output is high $(9.984 \mathrm{nV})$, otherwise low $(4.898 \mathrm{~V})$. It compares the reference lower limit of TSH that is 0.3 with recorded TSH level. It gives the high output $(9.984 \mathrm{nV})$ because $0.72>0.3$ as in Fig. 5 . 

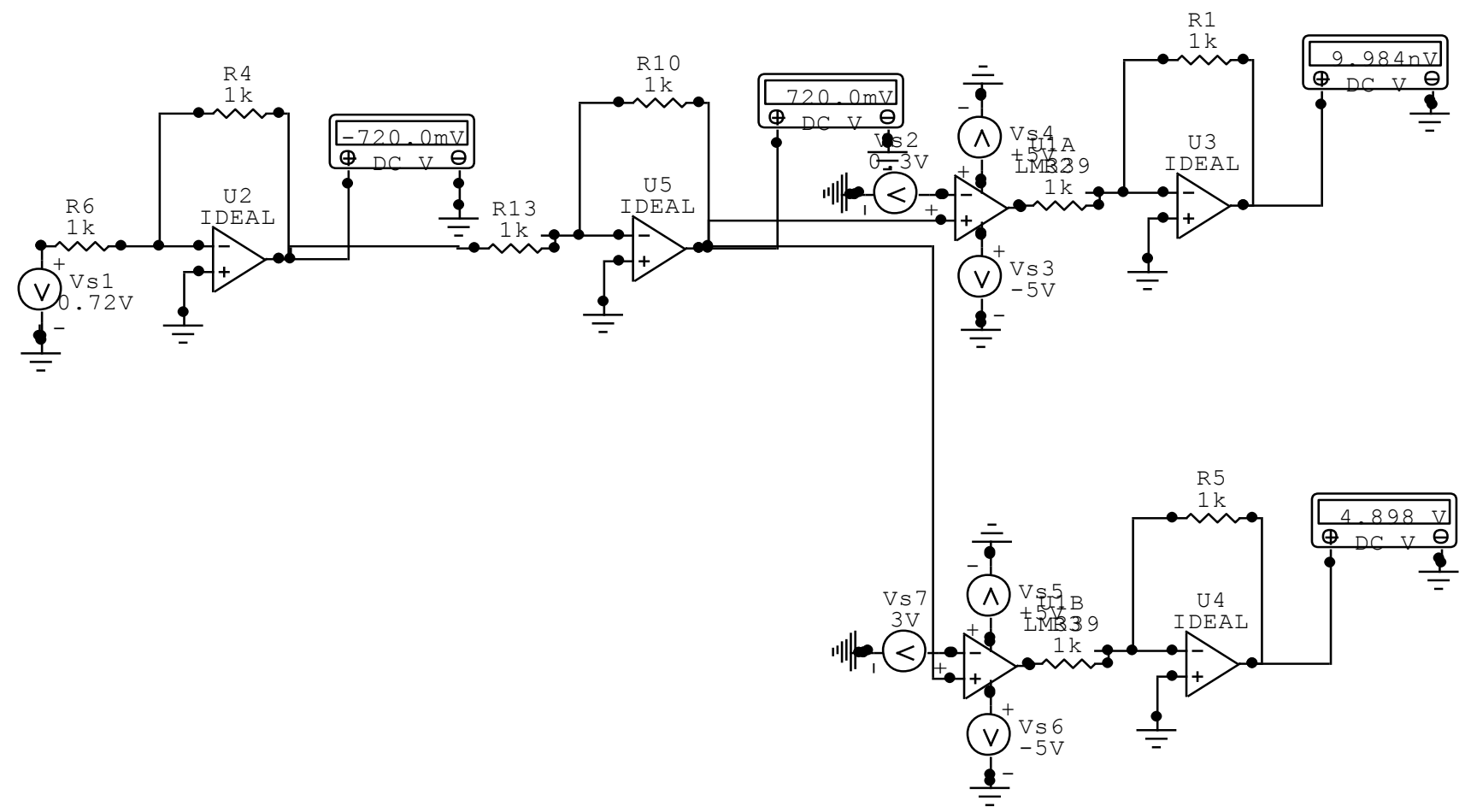

Fig. 5: Simulation for comparison of TSH, T3 and T4 using Circuit Maker

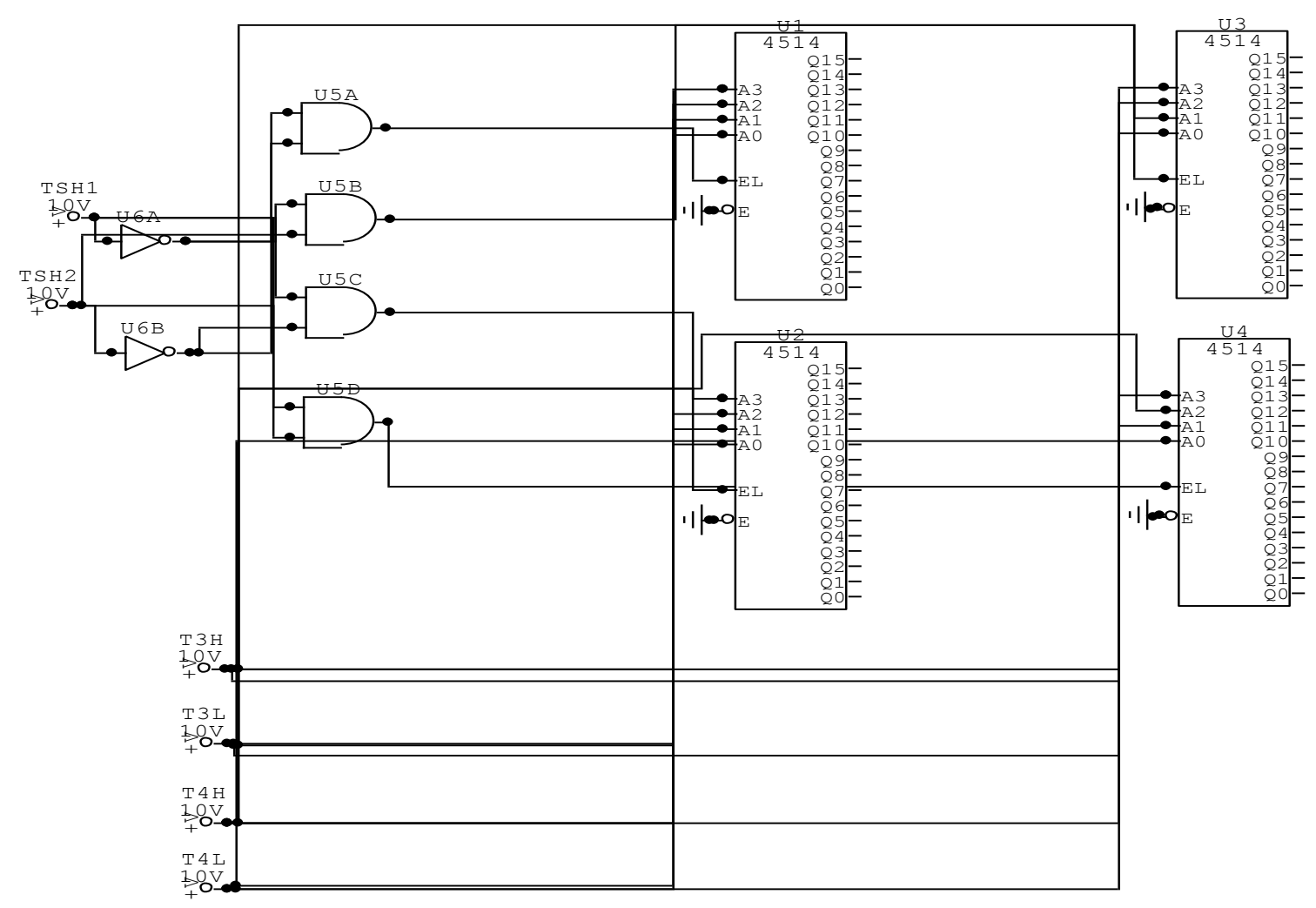

Fig. 6: Circuit for interpretation of type of Thyroidism

Similarly, the ideal OPAMP U1B is a comparator for comparing the higher limit that is $3.0 \mathrm{uIU} / \mathrm{mL}$ with the recorded TSH level. In the same way we can construct the circuits for Total T3 and Total T4 [22] and find the possibility of type of Thyroid disorder. The truth table for circuit for interpretation of Thyroid disease is given in Table IV. 
TABLE IV

TRUTH TABLE FOR DISEASES IN TABLE III

\begin{tabular}{|c|c|c|c|c|c|}
\hline TSH1 & TSH2 & T3H & T3L & T4H & T4L \\
\hline 0 & 0 & 0 & 0 & 0 & 0 \\
\hline 0 & 0 & 1 & 0 & 1 & 0 \\
\hline 0 & 0 & 1 & 1 & 1 & 1 \\
\hline 1 & 0 & 1 & 0 & 1 & 0 \\
\hline 1 & 1 & 0 & 0 & 0 & 0 \\
\hline 1 & 1 & 1 & 0 & 0 & 0 \\
\hline 1 & 1 & 1 & 0 & 1 & 0 \\
\hline 1 & 1 & 1 & 1 & 1 & 1 \\
\hline
\end{tabular}

\section{CONCLUSION}

The possible drawback of any analog computer simulation is so much assumption in deriving the relationships for operational amplifiers [20].It is difficult to get accuracy of measuring a voltage beyond a certain limit. We also have to dedicate an analog computer to one problem. Although there is widespread availability of Digital Computers, analog computers are preferred. The analog representation of a system is often more natural in the sense that it simplifies the implementation of simulation and understanding of the results. The use of analog computers is extended by developments in solid-logic electronic devices [18].

\section{FUTURE WORK}

Once the levels of the TSH, T3 and T4 are got and the type of disorder determined. The dosage can be calculated by applying interpolation and curve fitting methods in MATLAB and the corresponding best fitted equations can be implemented in the Circuit-maker [1]. And this is already in progress and being done by the authors.

\section{REFERENCES}

[1] Xiaobin Tang, ChangranGeng, Feida Chen, Yunpeng Liu, Da Chen Qin Xie, "The Simulation of Effective Dose of Human Body from External Exposure by Monte Carlo Methods," First International Workshop on Complexity and Data Mining, 2011.

[2] Jose Ramon Alvero, Cruz, Mauro Ronconi, Margarita, Carrillo De Albornoz, Gil, Jeronimo C., Garcia Romero, Daniel Rosado Velazquez, A. Mario De Diego Acosta, Thyroid hormones response in simulated laboratory sprint duathlon, Journal Of Human Sport \& Exercise, ISSN 1988-5202, 2011.

[3] Eisenberg M1, Samuels M, DiStefano JJ 3rd., Extensions, validation, and clinical applications of a feedback control system simulator of the hypothalamo-pituitary-thyroid axis, doi: 10.1089/ thy.2007. 0388, 2008.

[4] AACE press release of January 2003.

[5] Walter F., PhD. Boron , Chapter 48, "Synthesis of Thyroid Hormones Medical Physiology: A Cellular And Molecular Approach," Elsevier/Saunders. p. 1300. ISBN 1-4160-2328-3 2003.
[6] Oylum Şekera, Yaman Barlas and FarukAlagol, "Modeling The Dynamics Of Thyroid Hormones And Related Disorders," Industrial Engineering Department, Bogaziçi University, and Division of Endocrinology and Metabolism, Department of Internal Medicine, Istanbul Faculty of Medicine, Istanbul University.

[7] I.S. Isa, Z. Saad, S. Omar, M.K. Osman, K.A. Ahmad, H.A. Mat Sakim, "Suitable MLP Network Activation Functions for Breast Cancer and Thyroid Disease Detection," cimsim, pp.39-44, 2010 Second International Conference on Computational Intelligence, Modelling and Simulation, 2010.

[8] A. Mortoglou, H. Candiloros, "The serum triiodothyronine to thy- roxine (T3/T4) ratio in various thyroid disorders and after Levoth-yroxine replacement therapy," Department of Endocrinology, Diabetes and Metabolism, Athens Medical Centre Hospital, Athens, Greece.

[9] Leandro Martínez,Milton T. Sonoda,Paul Webb, John D. Baxter, Munir S. Skaf and Igor Polikarpov," Molecular Dynamics Simulations Reveal Multiple Pathways of Ligand Dissociation from Thyroid Hormone Receptors," Biophysical Journal, 2005.

[10] Professor G. Wainer, "Modelling and Simulation of the Human Liver," Biomedical Applications, Department of Systems and Computer Engineering, Faculty of Engineering, Carleton University.

[11] Georg Hennemann, Roelof Docter, Edith C. H. Friesema, Marion de Jong, Eric P. Krenning and Theo J. Visser, "Plasma Membrane Transport of Thyroid Hormones and Its Role in Thyroid Hormone Metabolism and Bioavailability, Endocrine Reviews". August 2001, 22(4):451-476.

[12] Modjtaba Rouhani, Kamran Mansouri ,"Comparison of Several ANN Architectures on the Thyroid Diseases Grades," International Association of Computer Science and Information Technology - Spring Conference, 2009.

[13] Jeffrey M. Blaney, Paul K. Weiner, Andrew Dearing, Peter A. Kollman, Eugene C. Jorgensen, Stuart J. Oatley, Jane M. Burridge, Colin C. F. Blake, Molecular mechanics, Simulation of protein-ligand interactions: binding of thyroid hormone analogs to prealbumin, Journal of the American Chemical Society, 1982.

[14] Journal of Clinical Endocrinology and Metabolism, August 1997.

[15] Granino Arthur Korn and Theresa M. Korn, Electronic Analog and Hybrid Computers, New York: McGraw-Hill Book Company, 1972.

[16] Murray, Francis J., Mathematical Machines, vol.2 Analog Devices, New York: Columbia Press, 1961.

[17] Walt Kester, Editor, High Speed Design Techniques, Analog Devices, 1996, ISBN0-916550-17-6. 
[18] Robert Paz, Analog Computer Programming

[19] Sergio Franco, Design with Operational Amplifiers and Analog Integrated Circuits, Second Edition, McGrawHill, 1998, pp.17-50

[20] Yash Pal, "An Analog Method to study Average Memory Access time in a compuer system," Proceedings of the World Congress on Engineering, 2013 Vol II, London, UK, 2013.
[21] Pierre-Frederic Villard, Piers Boshier, Fernando Bello and Derek Gould, "Virtual Reality Simulation of Liver Biopsy with a Respiratory Component." Imperial College, London, LORIA, Nancy University, Royal Liverpool Hospital, Liverpool.

[22] Alpco Diagnostics, "T4 (Thyroxine) (Free) LIA For the quantitative determination of of free T4 in serum," Version: 5.0 May 18, 2011 - ALPCO, 2012. 